\title{
The Relationship between Psychopathology, Self-esteem, Body Perception and Serum Sex Steroids in Pubertal Gynecomastia
}

\author{
Semiha Comertoglu Arslan ${ }^{1}$, Ibrahim Selcuk Esin ${ }^{2}$, Atilla Cayır ${ }^{3}$, Zerrin Orbak ${ }^{4}$, Onur Burak Dursun ${ }^{5}$ \\ ${ }^{1}$ Department of Child and Adolescent Psychiatry, Kahramanmaras Sutcu Imam University Medical Faculty, Kahramanmaras, ${ }^{2}$ Department of Child \\ and Adolescent Psychiatry, Ataturk University Medical Faculty, Erzurum, ${ }^{3}$ Department of Child Endocrinology, Training and Research Hospital, \\ Erzurum, ${ }^{4}$ Department of Child Endocrinology, Ataturk University Medical Faculty, Erzurum, ${ }^{5}$ Department of Child and Adolescent Psychiatry, \\ Trabzon Kanuni Training and Research Hospital, Trabzon, Turkey
}

\begin{abstract}
Objective: The current study aimed to investigate the psychopathology behind gynecomastia and potential associated problems regarding self-esteem and body perception, and the relationships of these variables with sex steroid levels in adolescents with pubertal gynecomastia.

Methods: The study included 50 normal weight male adolescents aged between 11 and 18 years with gynecomastia but without any chronic organic pathology, and 50 healthy pubertal male adolescents matched for age. The adolescents underwent psychopathology assessment by Development and Well-Being Assessment interviews; self-esteem was assessed using the Rosenberg Self-Esteem Scale; body perception was evaluated using the Body Image Perception Scale, and the relationship between these variables and sex steroid levels were explored.

Results: The results of the study revealed that the gynecomastia group had significantly greater internalization disorder $\left(\chi^{2}=12.96, p<0.001\right)$, and impairments in self-esteem $(z=-1.975, p=0.024)$ and body perception $(z=-2.286$, $p=0.022)$, and these variables were correlated with the gynecomastia stage. In the study group, cortisol levels were significantly higher $(z=-2.330, p=0.02)$ in adolescents with internalization disorder compared to those without, and cortisol levels increased in parallel with increased gynecomastia duration $(r=0.386, p=0.006)$.

Conclusion: In our study, we found that gynecomastia, depending on its stage, may lead to internalization disorder and impair self-esteem and body perception. It was found that there was no direct relationship between these parameters and sex steroids in pubertal gynecomastia, except for high cortisol levels in adolescents with internalization disorder.
\end{abstract}

KEY WORDS: Gynecomastia; Psychopathology; Self concept; Body image; Gonadal steroid hormones.

\section{INTRODUCTION}

Gynecomastia is defined as the concentric growth of one or both breasts due to the proliferation of the glandular component of the breast in the male [1]. Studies have shown that pubertal gynecomastia is seen in the

Received: July 9, 2020 / Revised: October 27, 2020

Accepted: December 15, 2020

Address for correspondence: Semiha Comertoglu Arslan Department of Child and Adolescent Psychiatry, Kahramanmaras Sutcu Imam Medical Faculty, Avşar Mah. Batı Çevreyolu Blv. No: 251/A 46040 Onikişubat/Kahramanmaraş, Turkey

E-mail: drsemihacrs@gmail.com

ORCID: https://orcid.org/0000-0002-2296-5853

This manuscript is part of a thesis for a Master's degree by Semiha Comertoglu Arslan, Onur Burak Dursun.

*The paper had only been published as a oral presentation, at 27th Turkish Child and Adolescent Psychiatry Congress, Turkey on May 10-13, 2017. community in a range of $30-60 \%[1,2]$. In the scientific literature, it is reported that pubertal gynecomastia usually begins between the ages of 10 and 12 years, reaches the highest frequency between 13 and 14 years, and involution occurs in most cases between the ages of 16 and 17 years [3]; however, about $10 \%$ of cases are persistent [2].

Several factors are thought to be responsible for the etiology of pubertal gynecomastia. It has been emphasized that the balance between the levels of sex steroid hormones such as estrogen and androgen may be the most effective mechanism in the etiology of gynecomastia, and several mechanisms such as increased estrogen production (increased serum and tissue concentration), decreased androgen production or hypersensitive breast tissue may be effective $[4,5]$. @ This is an Open-Access article distributed under the terms of the Creative Commons Attribution Non-Commercial License (http://creativecommons.org/licenses/by-nc/4.0)
which permits unrestricted non-commercial use, distribution, and reproduction in any medium, provided the original work is properly cited. 
Physical changes in adolescence have the potential to affect psychosocial development. Since it is incompatible with the male sex, gynecomastia may cause psychosocial difficulties and disrupt normal psychological development in this period [6,7]. Also, gynecomastia can lead to avoidance of activities where the body will be prominent and problems in all areas of interpersonal relations, potentially leading to decreased quality of life [8]. In the literature, psychopathologies such as depression, anxiety, social phobia, suicidal ideation, social isolation, school attendance problems, eating disorders, aggressive behavior, and a significant deterioration in social and academic processes have been reported in adolescents with pubertal gynecomastia [7-11].

Self-esteem is one of the basic structures that constitute adolescentive life, in other words, the core of one's identity, which determines the thoughts, feelings, and behaviors of an individual [12]. It has been reported that impairment of self-esteem may lead to the development of identity confusion, psychosomatic disorders, depression, eating and behavior disorders, and suicide [13-15]. Body perception is defined as a multidimensional structure with perceptual, affective, and cognitive components, and represents what someone thinks, feels, and behaves with regards their physical appearance. Body perception is thought to affect the emotional life and behavior of the individual, and it has been reported that the development of strategies to cope with difficult situations and social interaction are also affected $[16,17]$. Recent studies have shown that gynecomastia has adverse effects on the self-esteem and body perception of adolescents $[7,18]$.

Sex steroid hormones, which are thought to play a role in the etiology of gynecomastia, are also known to affect brain development and the etiology of neurodevelopmental disorders and may influence the development of psychiatric disorders during or after adolescence. The significant difference between the sexes after adolescence in terms of prevalence of psychiatric disorders suggests that sex hormones play a role in these disorders, but research on the underlying mechanisms is very limited. Gonadal hormones are thought to directly affect all neurotransmitter systems $[19,20]$. Studies reporting higher rates of anxiety disorders and major depressive disorder (MDD) in individuals with low testosterone levels support the claim that testosterone has positive effects on mental health [21]. In addition, several studies have also shown hypo- thalamus-pituitary-adrenal (HPA) axis irregularities in mood disorders [19].

To our knowledge, although there are limited studies on the frequency and diversity of psychopathologies in adolescents with gynecomastia, there are no studies on the determination of the biologic and psychosocial factors that may lead to the development of psychopathologies in these adolescents. The effects of self-esteem, body perception, and sex steroid hormones on susceptibility to psychopathology are not fully understood in gynecomastia. The aim of this study was to investigate the relationship between the development of psychopathologies and selfesteem, body perception, sex steroids, and other difficulties experienced due to gynecomastia. In addition, to determine the frequency and diversity of psychopathologies in individuals diagnosed as having gynecomastia.

\section{METHODS}

The study included a study group comprising 50 males who were admitted to Ataturk University Medical Faculty Pediatric Endocrinology Polyclinic between May 2013 and April 2015 with bilateral gynecomastia, who had no diagnosed any additional endocrinological, neurological, and psychiatric diseases. A control group consisting of 50 males with no gynecomastia and no additional endocrinological, neurological, and psychiatric diseases. Participants were in the normal weight range and aged between 11 and 18 years. None of the participants were using any psychotropic drugs or steroid drugs that may have affected their psychological or biological parameters. Informed consent was obtained from all participants and their families.

The participants were asked to complete a sociodemographic data form that had been prepared for the study. In order to determine the frequency and diversity of psychopathologies, the Development and Well-Being Assessment (DAWBA) interview was applied to participants and their families and a clinical evaluation was performed by a child and adolescents psychiatrist. Psychopathologies were assessed under two groups including internalization disorders and externalization disorders. In addition, the Rosenberg Self-Esteem Scale (RSES) and Body Image Perception Scale (BIPS) were used to assess the adolescents' self-esteem and body perception. Blood samples were collected to determine the levels of thyroid-stimulat- 
ing hormone (TSH), free T4, follicle-stimulating hormone $(\mathrm{FSH})$, leutinizing hormone $(\mathrm{LH})$, estradiol, total testosterone, prolactin, dehydroepiandrosterone sulfate (DHEA-S), cortisol, and sex hormone-binding globulin (SHBG), which were determined to be effective in the etiology of gynecomastia in the scientific literature.

Ethical approval for this study was obtained from Ataturk University Medical Faculty Ethics Committee on May 2nd, 2013 (4/14).

\section{Instruments}

\section{Sociodemographic data form}

The sociodemographic data form included questions regarding the adolescents' sociodemographic data, recognition time of gynecomastia, and difficulties experienced due to gynecomastia.

\section{Development and Well-Being Assessment}

DAWBA is a package of interviews, questionnaires, and rating techniques designed to generate psychiatric diagnoses in young people aged 5-17 years [22]. The instrument was translated and validated in Turkish by Dursun et al. [23]. DAWBA combines closed and openended questions about common child psychiatric disorders and their impact. Interviews can be administered either by interviewers or by computers. In this study, we used the computer-assisted self-administered form of DAWBA. In this study, an experienced child psychiatry who also validated the instrument made the diagnoses.

\section{Rosenberg Self-Esteem Scale}

RSES was developed by Rosenberg [24] in 1965 as a measure of self-esteem for adolescents. It is a global measure to assess positive and negative feelings about self. All 10 items are answered using a 4-point Likert scale format ranging from 'strongly agree' to 'strongly disagree'. The Turkish validity and reliability studies were conducted by Çuhadaroğlu [25]. Higher scores represent lower self-esteem.

\section{Body Image Perception Scale}

BIPS was developed by Secord and Jourand [26] in 1953, and the validity and reliability of the Turkish version were verified by Hovardaoğlu [27] in 1993. BIPS includes 40 items and higher points represent an increase in positive evaluation.

\section{Hormone Analysis}

Four $\mathrm{ml}$ venous blood samples were collected by a registered nurse from the antecubital vein to biochemistry tubes in the morning (at 09.00-11.00) after at least 10 hours of fasting. Serum TSH, free T4, FSH, LH, estradiol, total testosterone, prolactin, DHEA-S, cortisol, and SHBG were measured with the chemiluminescence method using kits from DXI 800 model (Beckman Coulter, Brea, CA, USA) fully automated hormone autoanalyzer. The costs of the kits were covered by the Ataturk University Scientific Research Project (2013/239).

\section{Statistics}

All analyses were performed using SPSS 20.0 (IBM Co., Armonk, NY, USA). Statistical significance was defined as $p<0.05$. We used the Kolmogorov - Smirnov test to analyze the normality of the data distribution. Either the Mann-Whitney $U$ test or Student's $t$ test were used depending on the distribution. Group differences were estimated using Pearson's Chi-square test and Fisher's exact test on categorical variables. We used Pearson's correlation analysis to identify correlations between numeric data of the study. Bonferroni correction was used to adjust the $p$ values for multiple comparisons.

\section{RESULTS}

There were no statistically significant differences between the study group and the control group in terms of age, height, body weight, body mass index (BMI), and socioeconomic income levels (all $p>0.05$ ). The age, height, body weight, and BMI of the adolescents are shown in Table 1.

When the groups were compared in terms of psychopathologies, there were 34 adolescents with internalization disorder in the study group and 16 adolescents with in-

Table 1. Clinical and demographic characteristics of the study and control groups

\begin{tabular}{lccc}
\hline Characteristic & $\begin{array}{c}\text { Study group } \\
(\mathrm{n}=50)\end{array}$ & $\begin{array}{c}\text { Control group } \\
(\mathrm{n}=50)\end{array}$ & $p$ value \\
\hline Age $(\mathrm{yr})$ & $13.7 \pm 1.5$ & $13.8 \pm 1.6$ & 0.633 \\
Weight $(\mathrm{kg})$ & $54.5 \pm 11.4$ & $52.5 \pm 11.1$ & 0.339 \\
Height $(\mathrm{cm})$ & $161.4 \pm 10.5$ & $162.3 \pm 11.8$ & 0.831 \\
BMI $\left(\mathrm{kg} / \mathrm{m}^{2}\right)$ & $20.6 \pm 2.6$ & $19.6 \pm 2.1$ & 0.812 \\
\hline
\end{tabular}

Values are presented as mean \pm standard deviation. $\mathrm{BMI}$, body mass index. 
ternalization disorder in the control group. The ratio of internalization disorders was significantly higher in the study group $\left(X^{2}=12.96, p<0.001\right)$. Six adolescents in the study group and 10 adolescents in the control group were diagnosed with externalization disorder. There was no significant difference between the groups in terms of externalization disorders $(p>0.05)$.

The RSES scores were found to be statistically significantly higher (lower self-esteem) $(z=-1.975, p=$ $0.024)$, and BIPS scores were significantly lower ( $z=-$ 2.286, $p=0.022$ ) in the study group than in the control group. The RSES scores and BIPS scores are shown in Table 2.

In the study group, BIPS scores were found to be negatively correlated $(r=-0.448, p=0.001)$, and RSES scores were positive correlated $(r=0.307, p=0.03)$ with the stage of gynecomastia.

The mean duration of diagnosis of gynecomastia was 12.9 months. There was no significant correlation between the duration of gynecomastia and RSES scores $(p>$ $0.05)$, whereas there was a significant negative correlation between the duration of gynecomastia and BIPS scores $(r=$ $-0.306, p=0.031$ ).
Distribution of the Study Group by Tanner Stage, Duration of Gynecomastia, Internalization Disorder, and Difficulties Experienced due to Gynecomastia are shown in Table 3.

When we compared adolescents who had and had not difficulties experienced due to gynecomastia, in the study group, we found that the group who experienced difficulties had a significantly higher ratio of internalization disorders (X2 $=4.427, p=0.035)$ and longer duration of gynecomastia ( $\mathrm{t}=2.214, p=0.032)$. These difficulties are tenderness and/or pain in the chest, being ridiculed, difficulty finding and choosing clothes, embarrassment by being close with people, problems in sports classes, and hunching.

When the groups were compared in terms of biologic parameters; testosterone levels were significantly lower in the study group $(z=-2.358, p=0.018)$; the estradiol/testosterone ratio was higher in the study group, but this difference was not statistically significant $(p>0.05)$. There was no statistically significant difference between the groups in terms of TSH, FSH, LH, prolactin, DHEA-S, cortisol, SHBG levels, DHEA-S/testosterone, and DHEA-S/E2 ratios (all $p>$ 0.05). There was no significant relationship between sex

Table 2. RSES and BIPS scores

\begin{tabular}{|c|c|c|c|c|c|c|c|}
\hline \multirow{2}{*}{ Variables } & \multicolumn{3}{|c|}{ Study group } & \multicolumn{3}{|c|}{ Control group } & \multirow{2}{*}{$p$ value } \\
\hline & Mean $\pm S D$ & Median & Min-Max & Mean $\pm S D$ & Median & $\operatorname{Min}-\operatorname{Max}$ & \\
\hline RSES score & $2.36 \pm 1.56$ & 2 & $0-6$ & $1.64 \pm 1.15$ & 1 & $0-4$ & 0.024 \\
\hline BIPS score & $145.68 \pm 27.28$ & 2 & $67-190$ & $157.78 \pm 19.06$ & 155.5 & $124-199$ & 0.022 \\
\hline
\end{tabular}

RSES, Rosenberg Self-Esteem Scale; BIPS, Body Image Perception Scale; SD, standard deviation.

Table 3. Distribution of the study group by Tanner stage, duration of gynecomastia, internalization disorder, and difficulties experienced due to gynecomastia

\begin{tabular}{|c|c|c|c|}
\hline Variables & Adolescents & $\begin{array}{l}\text { Adolescents with } \\
\text { internalization disorders }\end{array}$ & $\begin{array}{l}\text { Adolescents with difficulties } \\
\text { experienced due to gynecomastia }\end{array}$ \\
\hline \multicolumn{4}{|l|}{ Tanner stage } \\
\hline 1 & 6 & $1(16.7)$ & $1(16.7)$ \\
\hline 2 & 22 & $13(59.0)$ & $8(36.4)$ \\
\hline 3 & 21 & $19(90.5)$ & $10(47.6)$ \\
\hline 4 & 1 & $1(100)$ & $1(100)$ \\
\hline \multicolumn{4}{|l|}{ Duration } \\
\hline$<3$ months & 7 & $4(57.1)$ & $0(0)$ \\
\hline $3-6$ months & 9 & $4(44.4)$ & $4(44.4)$ \\
\hline 6 months -1 year & 5 & $4(80.0)$ & $3(60.0)$ \\
\hline $1-2$ years & 18 & $12(66.7)$ & $6(33.3)$ \\
\hline$>2$ years & 11 & $10(90.9)$ & $7(63.6)$ \\
\hline
\end{tabular}

Values are presented as number only or number (\%). 
steroids and having any psychopathology $(p>0.05)$. A positive correlation was found between the duration of gynecomastia and serum cortisol levels $(r=0.386, p=$ 0.006).

When the adolescents with internalization disorder and the other members in the study group were compared, those with internalization disorder had significantly longer durations of gynecomastia $(z=-2.330, p=0.02)$, more advanced stage of gynecomastia $(\mathrm{t}=4.102, p<$ 0.001), higher RSES scores (lower self-esteem) $(\mathrm{t}=2.390$, $p=0.019)$, lower BIPS scores $(\mathrm{z}=-2.808, p=0.005)$, and higher serum cortisol levels $(z=-2.330, p=0.02)$. There was no significant difference between the diagnosed group and the non-diagnosed group in terms of externalization disorders in the study group $(p>0.05)$. The significant association between internalization disorder in adolescents and gynecomastia stage and BIPS scores remained after applying the Bonferroni correction.

\section{DISCUSSION}

In this study, we investigated the psychopathology of and self-esteem and body perception in gynecomastia, and the relationships between thesse variables and sex steroids in 11-18 year-old adolescents with gynecomastia. To the best of our knowledge, this is the first study to investigate the biologic and psychosocial factors associated with the development of any psychopathology in adolescents with gynecomastia.

One of the most important findings of this study is that adolescents with gynecomastia have significantly more internalization disorders than those without gynecomastia. Although there are case reports of adolescents with gynecomastia who presented with depression, anxiety, eating disorders, and aggressive behaviors in the literature, we found only one case report using validated psychiatric instruments for the evaluation of adolescents [7-10,28]. Schonfeld [8] reported symptoms of anxiety in about half of 25 adolescents with gynecomastia. Kinsella et al. [7] compared 24 adolescents with gynecomastia aged between 12 and 18 years with the general population in terms of anxiety, depression, and social phobia and found that all of the adolescents were diagnosed according to the Diagnostic and Statistical Manual of Mental Disorders-IV. The diagnoses were determined as adjustment disorder $(79.2 \%)$, anxiety disorder $(16.7 \%)$, dysthymia $(16.7 \%)$, generalized anxiety disorder (4.2\%), and social phobia $(4.2 \%)$. In our study, similar to the literature, we found that the ratio of psychopathologies, especially internalization disorders, was significantly higher in the study group.

In the literature, it was emphasized that gynecomastia might impair normal psychological development, have negative effects on self-esteem and sexual identity, and that these adolescents might experience at least one adjustment disorder, and psychiatric treatment for adolescents with gynecomastia was recommended in addition to medical treatment [7]. Similarly, our findings revealing that those with internalization disorders have a longer duration of gynecomastia and lower levels of self-esteem and body perception, lay emphasis on the importance of early intervention in these adolescents.

Adolescence is considered to be the most critical process regarding the development of self-esteem. In this period, adolescents experience significant changes in relations with parents and their immediate surroundings, which are thought to have important effects on self-esteem [29]. In a study by Kinsella et al. [7], it was determined that the majority of adolescents with gynecomastia reported a decrease in their self-esteem, and these adolescents reported a negative self-image. Although many publications in the literature have indicated that gynecomastia may reduce self-esteem, only one study evaluated self-esteem using a standardized scale. Nuzzi et al. [18] used the RSES and found that adolescents with gynecomastia had lower self-esteem than those without gynecomastia. We found self-esteem to be significantly lower in the study group, and as opposed to body perception, we found no statistically significant relationship between self-esteem and duration of gynecomastia, whereas we found a statistically significant positive correlation between the stage of gynecomastia and self-esteem. This result suggests that self-esteem is affected by the stage of gynecomastia rather than the duration of gynecomastia. As mentioned above, it can be interpreted that gynecomastia at a level that disturbs the external visual image and body perception may also directly affect self-esteem.

Adolescence is a period when great changes in an individual's body are experienced and the awareness of the body increases [16]. During adolescence, normal physiologic changes can be experienced as well as changes that can be considered as a medical condition such as 
gynecomastia. Gynecomastia may present as an important problem that can affect body perception as well as self-esteem because this is not a compatible situation for male sex [30]. Similar to the literature, we found that the body perception scores of the study group were significantly lower and decreased as the duration of gynecomastia prolonged.

Self-esteem and body-perception are closely related concepts and affect each other within a cause-effect relationship [31]. In accordance with the literature, we observed a significant relationship between body perception and self-esteem.

In our study, the significantly lower body image scores and self-esteem scores of adolescents diagnosed as having an internalization disorder in comparison with adolescents without an internalization disorder may be related to the development of psychopathologies. Decrease in self-esteem, distorted body perception, difficulties experienced in social environments, and the way adolescents perceived themselves could have all supported the development of disorders.

It has previously been shown that the level of psychological effects of gynecomastia can vary from stage 1 to stage $4[6,7]$. In our study, we found that as the stage gynecomastia increased, self-esteem decreased, body-perception worsened, and the duration of gynecomastia became longer. Additionally, the incidence of internalization disorders was found to increase as the stage of gynecomastia increased. Furthermore, the finding that the significant association between gynecomastia stage and internalization disorder after applying the Bonferroni correction may suggest that disease stage is an important factor for the development of internalization disorder. However, Nuzzi et al. [18] emphasized that the stage of gynecomastia was not effective in determining psychosocial adjustment problems and the degree of impairment.

Gynecomastia may also cause many problems in everyday life. In the literature, adolescents with gynecomastia described swelling and tenderness in the early phase. As the duration of gynecomastia is prolonged and the breast disc becomes more apparent, emotional findings are added [32]. Esenboğa et al. [30] reported that adolescents with gynecomastia preferred to abstain from sports activities such as swimming, and wore large clothes and requested urgent solutions before the summer holidays began. In a study conducted by Kinsella et al. [7], adoles- cents with gynecomastia reported that gynecomastia caused significant impairment in their social and/or academic functioning and that they were ridiculed by others. In our study, in addition to the difficulties experienced, it was determined that the longer the duration of gynecomastia, the greater the risk of experiencing difficulties in daily life. These difficulties include tenderness and/or pain in the chest, being ridiculed, difficulty in finding and choosing clothes, embarrassment by being close with people, problems in sports classes, and hunching. Significantly more internalization disorders have been identified in adolescents who experience one or more of these difficulties due to gynecomastia. When all of the findings were evaluated as a whole, similar to the literature, it can be suggested that gynecomastia may cause various difficulties in daily life. Our findings suggest that in the context of psychosocial support for gynecomastia, handling the difficulties experienced in life may be protective against the development of psychopathologies.

Several studies showed that serum testosterone levels may be effective in the etiopathogenesis of gynecomastia. In a longitudinal study by Biro et al. [33], free testosterone levels in individuals with gynecomastia at 6 months before the diagnosis and at the beginning of gynecomastia were found to be significantly lower than in those without gynecomastia. In accordance with the literature, the total serum testosterone levels of the adolescents with gynecomastia in our study were significantly lower than in control groups. Testosterone is a hormone that can affect all organs and systems and it may have important effects on many aspects of life. A number of studies have examined the relationship between testosterone and psychopathologies [34]. It has been reported that testosterone levels decreased in males in various stress-causing conditions such as tournaments, examinations, and various encountered troubles, and then increased with the disappearance of the stress factor. The decrease of testosterone levels after exposure to stressors may be due to a decreased secretion of $\mathrm{LH}$ or lack of adequate response at the pituitary level [34]. In our study, although lower testosterone levels and more psychopathologies were determined in the study group when compared with the control group, suggesting a possible relationship between testosterone and psychopathologies, we found no significant relationship between having any psychopathology and testosterone levels.

It has been well documented that the HPA axis is acti- 
vated and cortisol is released in response to stress. This response occurs in the event of physical stress and during psychologically disturbing events. Data regarding psychological stress and HPA-axis response in the adolescent population are limited. When adolescents with depression were compared with healthy controls, it was found that those with depression had higher cortisol levels during the day and gave irregular responses to the dexamethasone suppression test [35]. In a prospective study of adolescents with a high risk of psychopathology, daily morning cortisol peak levels were found to be significantly higher and MDD developed in these adolescents in the following period [36]. HPA-axis disorder is not only specific to depression, it is also important in other disorders such as post-traumatic stress disorders and social anxiety [35]. In our study, cortisol levels in the group with internalization disorders were significantly higher than the group without an internalization disorder. In addition, as an important finding, we found that cortisol levels were significantly associated with the duration of gynecomastia. These findings may suggest that cortisol can play a role in internalization disorder in adolescents with gynecomastia. There is a need for further studies to clarify the role of cortisol in psychopathologies that may develop in adolescent with pubertal gynecomastia.

Although our study provides some valuable information about the structure of gynecomastia that affects daily life and disrupts functionality, the limitations of our study should be considered. The first limitation of the study is that the sample size is relatively small. Other limitations of the study include the fact that measuring values in the morning may be insufficient to reflect the 24-h hormone levels because the measured hormones have circadian rhythms, and the age group of the individuals involved in the study was adolescence, when biologic changes occur and sensitivity to psychosocial factors increases. This should be taken into account when making general conclusions from the study results. The strengths of the study include being a randomized, controlled trial, and the exclusion of obese adolescents because obesity may have possible effects on the development of psychopathologies through biologic and psychosocial factors.

It should be taken into account that gynecomastia may cause psychopathologies that impair functionality, and it may lead to adverse effects on self-esteem and body per- ception in the adolescents. As far as we know, our study is the first in the literature to include clinical interviews and structured interviews in terms of all psychopathologies. With regards to the literature and our study findings, we conclude that gynecomastia is a psychoendocrine disorder and similar to psychiatric diseases, psychosocial stressors on genetic and biologic bases may contribute to the development of psychopathologies. In our study, although the gynecomastia group had significantly greater psychopathologyies, there was no direct relationship between impairments in self-esteem and body perception and sex steroids. However, gynecomastia duration and stage were found to be more effective on psychopathology, self esteem, and body perception in gynecomastia. It was found that cortisol was higher in adolescents with internalization disorder in the study group and was associated with gynecomastia duration.

It should not be forgotten that informing adolescents and their families about the disease process and the psychiatric problems that may develop, and encouraging behavioral approaches that may improve self-esteem and body perception in the early phase can contribute to the prevention of future psychopathologies, as well as the deterioration of difficulties experienced.

\section{- Acknowledgments}

This research was supported by Atatürk University Scientific Research Projects Coordination Unit with the PRJ 2013/239 Project Code.

\section{Conflicts of Interest}

No potential conflict of interest relevant to this article was reported.

\section{- Author Contributions}

Conceptualization: Semiha Comertoglu Arslan, Onur Burak Dursun. Data acquisition: Semiha Comertoglu Arslan, Atilla Cayır, Zerrin Orbak. Supervision: Ibrahim Selcuk Esin, Onur Burak Dursun. Writing - original draft: Semiha Comertoglu Arslan, Onur Burak Dursun. Writingreview \& editing: Semiha Comertoglu Arslan, Ibrahim Selcuk Esin, Onur Burak Dursun.

\section{ORCID}

Semiha Comertoglu Arslan

https://orcid.org/0000-0002-2296-5853 
Ibrahim Selcuk Esin https://orcid.org/0000-0001-5598-2097

Atilla Cayır https://orcid.org/0000-0001-9776-555X

Zerrin Orbak https://orcid.org/0000-0002-1847-9844

Onur Burak Dursun https://orcid.org/0000-0003-2990-9851

\section{REFERENCES}

1. Johnson RE, Kermott CA, Murad MH. Gynecomastia- evaluation and current treatment options. Ther Clin Risk Manag 2011;7:145-148.

2. Ordaz DL, Thompson JK. Gynecomastia and psychological functioning: a review of the literature. Body Image 2015;15: 141-148.

3. Cuhaci N, Polat SB, Evranos B, Ersoy R, Cakir B. Gynecomastia: clinical evaluation and management. Indian J Endocrinol Metab 2014;18:150-158.

4. Abaci A, Buyukgebiz A. Gynecomastia: review. Pediatr Endocrinol Rev 2007;5:489-499.

5. Ismail AA, Barth JH. Endocrinology of gynaecomastia. Ann Clin Biochem 2001;38(Pt 6):596-607.

6. Rohrich RJ, Ha RY, Kenkel JM, Adams WP Jr. Classification and management of gynecomastia: defining the role of ultrasound-assisted liposuction. Plast Reconstr Surg 2003;111: 909-923; discussion 924-925.

7. Kinsella C Jr, Landfair A, Rottgers SA, Cray JJ, Weidman C, Deleyiannis FW, et al. The psychological burden of idiopathic adolescent gynecomastia. Plast Reconstr Surg 2012;129:1-7.

8. Schonfeld WA. Gynecomastia in adolescence: effect on body image and personality adaptation. Psychosom Med 1962;24: 379-389.

9. Schonfeld WA. Gynecomastia in adolescence. Personality effects. Arch Gen Psychiatry 1961;5:46-54.

10. Fisher M, Fornari V. Gynecomastia as a precipitant of eating disorders in adolescent males. Int J Eat Disord 1990;9:115119.

11. Losee JE, Jiang S, Long DE, Kreipe RE, Caldwell EH, Serletti JM. Macromastia as an etiologic factor in bulimia nervosa: 10-year follow up after treatment with reduction mammaplasty. Ann Plast Surg 2004;52:452-457; discussion 457.

12. Rosenberg M. Society and the adolescent self-image. Princeton:Princeton University Press;2015.

13. Coleman JC, Hendry LB. The nature of adolescence. Hove: Psychology Press; 1999.

14. Silverstone PH, Salsali M. Low self-esteem and psychiatric patients: part I - the relationship between low self-esteem and psychiatric diagnosis. Ann Gen Hosp Psychiatry 2003;2:2.

15. Yoo T, Kim SW, Kim SY, Lee JY, Kang HJ, Bae KY, et al. Relationship between suicidality and low self-esteem in patients with schizophrenia. Clin Psychopharmacol Neurosci 2015;13:296-301.

16. McGrath $\mathrm{MH}$, Mukerji S. Plastic surgery and the teenage patient. J Pediatr Adolesc Gynecol 2000;13:105-118.

17. Cotton N. Normal adolescence. In: Sadock BJ, Sadock VA, editors. Kaplan \& Sadock's comprehensive textbook of psychiatry. Philadelphia:Lippincott Williams \& Wilkins;2000. p.2551-2552.

18. Nuzzi LC, Cerrato FE, Erikson CR, Webb ML, Rosen H, Walsh EM, et al. Psychosocial impact of adolescent gynecomastia: a prospective case-control study. Plast Reconstr Surg 2013; 131:890-896.

19. Fernández-Guasti A, Fiedler JL, Herrera L, Handa RJ. Sex, stress, and mood disorders: at the intersection of adrenal and gonadal hormones. Horm Metab Res 2012;44:607-618.

20. Martel MM, Klump K, Nigg JT, Breedlove SM, Sisk CL. Potential hormonal mechanisms of attention-deficit/hyperactivity disorder and major depressive disorder: a new perspective. Horm Behav 2009;55:465-479.

21. McHenry J, Carrier N, Hull E, Kabbaj M. Sex differences in anxiety and depression: role of testosterone. Front Neuroendocrinol 2014;35:42-57.

22. Goodman R, Ford T, Richards H, Gatward R, Meltzer H. The Development and Well-Being Assessment: description and initial validation of an integrated assessment of child and adolescent psychopathology. J Child Psychol Psychiatry 2000; 41:645-655.

23. Dursun OB, Guvenir T, Aras S, Ergin C, Mutlu C, Baydur H, et al. A new diagnostic approach for Turkish speaking populations DAWBA Turkish Version. Epidemiol Psychiatr SCi 2013;22:275-282.

24. Rosenberg M. Society and the adolescent self-image. Princeton:Princeton University Press; 1965.

25. Çuhadaroğlu F. Adolesanlarda benlik saygısı. Ankara:Hacettepe University; 1986. [Dissertation].

26. Secord PF, Jourard SM. The appraisal of body-cathexis: bodycathexis and the self. I Consult Psychol 1953;17:343-347.

27. Hovardaoğlu S. [Vücut algısı ölçeği. Psikiyatri, psikoloji, psikofarmakoloji dergisi (3P)]. Testler Özel Eki 1993;1:26-27. Turkish.

28. Storch EA, Lewin AB, Geffken GR, Heidgerken AD, Stawser MS, Baumeister A, et al. Psychosocial adjustment of two boys with gynecomastia. J Paediatr Child Health 2004;40:331.

29. Shi J, Wang L, Yao Y, Su N, Zhao X, Zhan C. Family function and self-esteem among Chinese university students with and without grandparenting experience: moderating effect of social support. Front Psychol 2017;8:886.

30. Esenboğa S, Akgül S, Kanbur N, Tüzün Z, Derman O. The effect of gynecomastia on body image perception and gender roles in adolescents. Turk J Pediatr 2015;57:60-67.

31. Green MA, Scott NA, Cross SE, Liao KY, Hallengren JJ, Davids $\mathrm{CM}$, et al. Eating disorder behaviors and depression: a minimal relationship beyond social comparison, self-esteem, and body dissatisfaction. J Clin Psychol 2009;65:989-999.

32. Kilic M, Kanbur N, Derman O, Akgül S, Kutluk T. The relationship between pubertal gynecomastia, prostate specific antigen, free androgen index, SHBG and sex steroids. J Pediatr Endocrinol Metab 2011;24:61-67.

33. Biro FM, Lucky AW, Huster GA, Morrison JA. Hormonal stud- 
ies and physical maturation in adolescent gynecomastia. J Pediatr 1990;116:450-455.

34. Zitzmann M, Nieschlag E. Testosterone levels in healthy men and the relation to behavioural and physical characteristics: facts and constructs. Eur J Endocrinol 2001;144:183-197.

35. Lopez-Duran NL, Kovacs M, George CJ. Hypothalamic-pituitary-adrenal axis dysregulation in depressed children and adolescents: a meta-analysis. Psychoneuroendocrinology 2009;34:1272-1283.

36. Goodyer IM, Herbert J, Tamplin A, Altham PM. Recent life events, cortisol, dehydroepiandrosterone and the onset of major depression in high-risk adolescents. Br J Psychiatry 2000;177:499-504. 